\title{
Umbilical artery doppler flow patterns in high-risk pregnancy and foetal outcome in Mulago hospital
}

\author{
P. Komuhangi ${ }^{1^{*}}$, R. K. Byanyima ${ }^{2}$, E.Kiguli-Malwadde ${ }^{3}$, C. Nakisige ${ }^{4}$ \\ ${ }^{1}$ ECUREI, Mengo Hospital, Kampala, Uganda; \\ *Corresponding Author: patriciakomuhangi@yahoo.com \\ ${ }^{2}$ Radiology Department, Mulago Hospital, Kampala, Uganda \\ ${ }^{3}$ African Centre for Global Health and Social Transformation (ACHEST), Kampala, Uganda \\ ${ }^{4}$ Department of Obstetrics and Gynaecology, Mulago Hospital, Kampala, Uganda
}

Received 21 January 2013; revised 20 February 2013; accepted 18 March 2013

Copyright (C) 2013 P. Komuhangi et al. This is an open access article distributed under the Creative Commons Attribution License, which permits unrestricted use, distribution, and reproduction in any medium, provided the original work is properly cited. In accordance of the Creative Commons Attribution License all Copyrights (C) 2013 are reserved for SCIRP and the owner of the intellectual property P. Komuhangi et al. All Copyright (C) 2013 are guarded by law and by SCIRP as a guardian.

\section{ABSTRACT}

Objective: To demonstrate the flow patterns and factors associated with adverse foetal outcome in high-risk pregnancy at Mulago Hospital using Doppler ultrasound of the foetal umbilical artery. Design: Cross-sectional descriptive study. Setting: Mulago National Referral Hospital, Kampala Uganda. Study Subjects: One hundred and ninetytwo patients in a 4-month period (December 2008-April 2009). Results: Maternal age was 16 to 41 years. Twenty-one foetuses had abnormal flow patterns (12 had reduced end-diastolic flow, 8 had AEDF and 1 had RF). Prematurity was associated with abnormal flow patterns. 11 out of 12 foetuses with reduced end-diastolic flow survived. Of the foetuses with AEDF, 3 survived but were admitted to the neonatal special care unit while 5 died. One foetus had RF and was a stillbirth. Eighteen foetuses were delivered after an obstetric intervention. Conclusions: 1) The prevalence of abnormal flow patterns is $10.9 \%$. 2) Abnormal flow patterns, low biophysical profile score, premature delivery, low birth weight and low Apgar score are related to adverse foetal outcome. 3) A low biophysical profile score is related to AEDF/RF. 4) Foetuses of low parity mothers are more likely to have abnormal flow patterns. Recommendation: Umbilical artery Doppler Biophysical profile scores should be done in high-risk pregnancy.

Keywords: Doppler; Umbilical Artery

\section{INTRODUCTION}

High-risk pregnancy constitutes conditions that predispose to placental insufficiency. These cause foetal compromise and are detected early by combined antepartum surveillance methods saving infant lives as well as reducing foetal disabilities [1].

High-risk pregnancy is a situation in which the mother has a condition likely to cause an adverse effect on the foetus. High-risk groups include women with: a previous complicated pregnancy, insulin dependent diabetes connective tissue diseases, phenylketonuria, age over 35 years, alcohol and drug dependence, maternal infections such as rubella, cytomegalovirus and toxoplasmosis [2]. According to the Uganda Clinical Guidelines (2003), a high-risk pregnancy is one with a risk of an adverse outcome for the mother or baby [3]. The criteria for highrisk pregnancy are extremes of reproductive age (below 18 or greater than 35 years), young primigravida, high parity or short birth interval, large infants of 4 kilograms or more, prematurity, low birth weight of less than 2.5 kilograms, obstructed and difficult labours, poor obstetric history, history of reproductive tract surgery, genetic or familial diseases, medical conditions such as diabetes, cardiac or renal disease, hypertension, rhesus incompatibility, maternal disabilities, those with obstetric risks such as multiple pregnancy, malpresentations and others, antepartum haemorrhage, postpartum haemorrhage, deep vein thrombosis, intrauterine growth retardation, premature rupture of membranes, post dates and cephalopelvic disproportion [4].

Hypertension may cause abnormal flow patterns in the umbilical artery and other foetal vessels. Diabetes predisposes pregnant mothers to preeclampsia and eclamp- 
sia. Abnormal flow velocities may be seen in the umbilical and uterine arteries in foetal growth retardation [5].

Doppler ultrasound besides other obstetric tests can detect impeding foetal hypoxia [5]. Reversal of flow or absent end-diastolic flow in the umbilical artery shows foetal compromise [1]. Doppler ultrasound in high-risk pregnancies improves a number of obstetric care outcomes and appears promising in helping to reduce perinatal deaths [6]. The intrapartum stillbirths are 14 times more in developing than developed countries [7].

The perinatal mortality rate in Uganda is 53 per 1000 live births, infant mortality 88 per 1000 live births and neonatal mortality is $41 \%$ of all infant deaths [8,9]. In Mulago Hospital, there are about 15 neonatal deaths per 1000 births [9] and the still birth rate is 23 per 1000 births [10]. High-risk pregnancy is associated with a high rate of obstetric intervention in a bid to save the mother's and/or baby's life.

Doppler ultrasound is available in Mulago Hospital, therefore, it can be done in high-risk pregnancies to detect foetal compromise and intervention, if necessarily instituted to save infant lives. This study was aimed to demonstrate the Doppler foetal umbilical artery flow patterns and their relationship with the foetal outcome at Mulago Hospital.

\section{MATERIALS AND METHODS}

The study was carried out in Mulago National Referral Hospital.

Informed consent was obtained from all the study participants. The sample size was calculated using Kish and Leslie's formula [42] for cross-sectional studies and it came to 202 participants. 192 (94\%) patients were, however, recruited due to limited resources.

\subsection{Inclusion Criteria}

All high-risk pregnancy mothers of 28 weeks gestational age and above who attended antenatal clinic or were admitted in the obstetric wards from December 2008 to April 2009.

\subsection{Exclusion}

Multiple pregnancy mothers and those in labour.

Real time ultrasound with a curvilinear $3.5 \mathrm{MHz}$ probe and Doppler was used. The umbilical arteries were identified by colour-flow mapping and one artery sampled at random. With the Doppler power settings set as low as possible, using a minimal wall filter, the Doppler measurements were done away from the cord insertion of the umbilical artery where the audible signal was highest (i.e. where flow was maximum) $[43,44]$. The Doppler recordings were made with the angle of insonation be- tween the Doppler beam and direction of flow less than 30 degrees [45]. The mothers were told to hold their breaths when recording the Doppler spectra [1]. The resistance indices were calculated using the formula: systolic-diastolic flow/systolic flow. The biophysical profile was done for each pregnancy.

\section{RESULTS}

One hundred and ninety-two patients were recruited. Their age range was 16 to 41 years of age. Thirty-four percent of the patients were in the 21 - 25 year age range. The mean age of the patients was 23 , the median age was 28.5 and the mode was 23 years.

One hundred and seventy-four $(90 \%)$ of the mothers had hypertension in pregnancy, $14(7 \%)$ had IUGR without hypertension while 8 had IUGR with hypertension and $4(2 \%)$ had Diabetes Mellitus.

All the mothers were residing in the central region around the city of Kampala.

\subsection{Prevalence of Abnormal Umbilical Artery Doppler Flow Patterns}

The prevalence of abnormal flow patterns in Mulago Hospital according to this study was $10.95 \%$ and these included: reduced end-diastolic flow (6.25\%), AEDF $(4.2 \%)$ and RF $(0.5 \%)$.

All the foetuses with AEDF/RF were delivered prematurely, 8 by obstetric intervention i.e. 4 by caesarian section and 4 after induction of labour. This is statistically significant. $\mathrm{P}=0.0004$ OR 17.54 (1.98 - 155.4).

The majority of foetuses with AEDF and RF had low birth weights (less than $2.5 \mathrm{~kg}$ ); 5 of them weighed less than $1.5 \mathrm{~kg}$. Most were admitted to the neonatal special care unit. This was a high rate of still/births among foetuses with AEDF/RF. P $=<0.0001$ OR 38.7 (6.61 - 226).

Of the twelve foetuses with reduced end diastolic flow, $8(66.7 \%)$ were born prematurely but the most survived. Nine of them (75\%) had a good Biophysical profile score and $8(66.7 \%)$ had an Apgar score of 8 - 10 .

Ten of the foetuses $(83 \%)$ were delivered by obstetric intervention, 6 by caesarian section and 4 by induction of labour. The birth weights of the foetuses were $\leq 2.5 \mathrm{~kg}$ for 7 of the foetuses and of these 2 were below $1.5 \mathrm{~kg}$.

The foetuses with AEDF/RF were more at risk of having an adverse outcome than the ones with normal flow patterns. There were only 9 foetuses $(5 \%)$ with adverse outcomes among those with normal flow patterns.

Five of the 9 foetuses with AEDF/RF had a low biophysical profile score.

Nine of the 12 foetuses with reduced end-diastolic flow $(75 \%)$ had a good biophysical profile score of 8 to 10.

A sub-analysis of the resistance indices of 150 patients 
was done. The resistance indices ranged from 0.21 to 0.88 . Thirty-two of the $34(94 \%)$ foetuses with high umbilical artery resistance indices were of hypertensive mothers.

Foetuses delivered at 28 - 36 weeks were 3 times more likely than those delivered at $37-42$ weeks to have had a high umbilical artery resistance index. OR 3.17 (CI 1.40 - 7.17) $\mathrm{P}=0.00$. This is statistically significant. A big proportion of the foetuses with high umbilical artery resistance indices $(88 \%)$ had an obstetric intervention and of these $18(53 \%)$ were delivered by caesarian section.

High resistance indices were not associated with poor foetal outcome.

High umbilical artery resistance indices were not associated with a low biophysical profile score $(8-10)$.

\section{DISCUSSION}

A cross-sectional descriptive study on the umbilical artery Doppler flow patterns in high-risk pregnancy and foetal outcome in Mulago Hospital which is in the city of Kampala, Uganda was done.

Most of the study patients were in the age range of 21 - 25 years. This is because it is when most women have their children in Uganda. It is just after the age of consent (18 years). Many women leave school early so they tend to start having children at an early age.

Eighty-four percent of the mothers were multiparous. Pregnancy-induced hypertension, which most of the mothers had has been reported to be common among nulliparous women by some studies [45,46]. It is also reported that PIH occurs in multiparous women because of increased incidence of chronic hypertension with increasing maternal age [4]. The fertility rate in Uganda is one of the highest in the world (6.5 in 2007) [47] and there is no government limit on how many children a couple can have. The infant mortality rate is high and most mothers want many children because of the belief that if some children die, they can retain some. Since Mulago Hospital is a national referral hospital, many multiparous mothers also come because they are referred from the peripheral units.

The prevalence of abnormal flow patterns in Mulago Hospital according to this study was $10.95 \%$ with reduced end-diastolic flow (Figure 1) being 6.25\%, AEDF (Figure 2) $4.2 \%$ and RF (Figure 3) $0.5 \%$. This is almost the same as reported in literature i.e. is $5 \%-8 \%$ for AEDF and $0.5 \%$ for RF [1] although it was a little bit lower. This could be that some of the mothers whose foetuses had abnormal flow patterns were missed since some of them deliver from home or the smaller health units with no Doppler ultrasound machines. A total of 21 foetuses had abnormal flow patterns (12 with reduced end-diastolic flow, 1 with RF and 8 with AEDF). These were seen among foetuses with IUGR and those whose

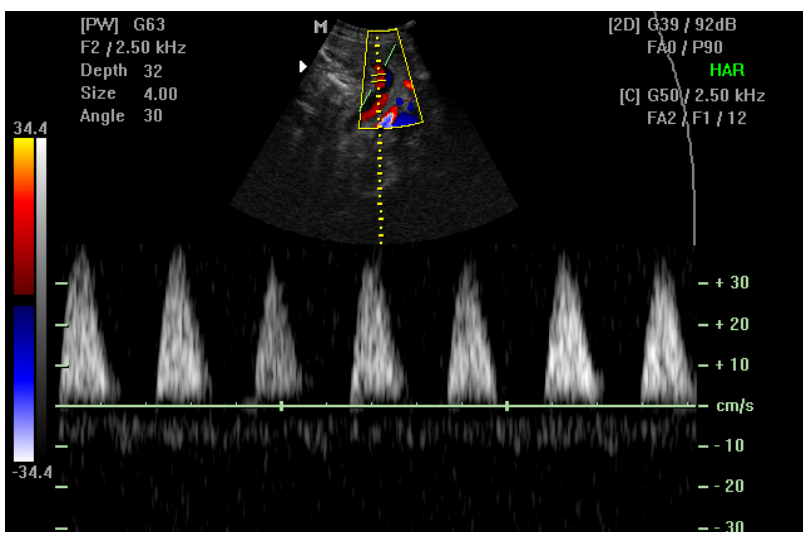

Figure 1. An example of reduced end-diastolic flow in Mulago Hospital.

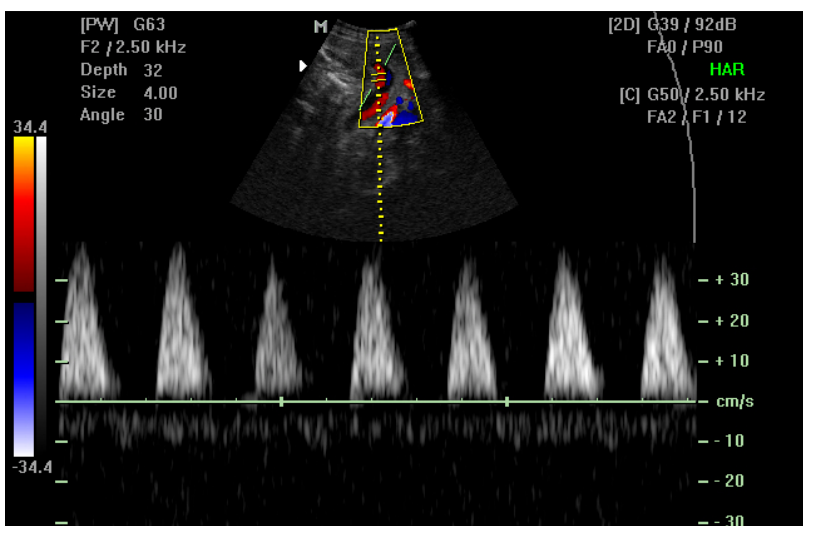

Figure 2. AEDF in the foetal umbilical artery. The mother was 26 years old and had pregnancy-induced hypertension. The foetus was delivered prematurely by Caesarian section, admitted to neonatal special care unit and died within 24 hours of delivery. It was less than $2.5 \mathrm{~kg}$. A similar flow pattern was seen in 7 other foetuses, 4 of whom died ( 2 in utero and 2 after delivery) and 3 survived.

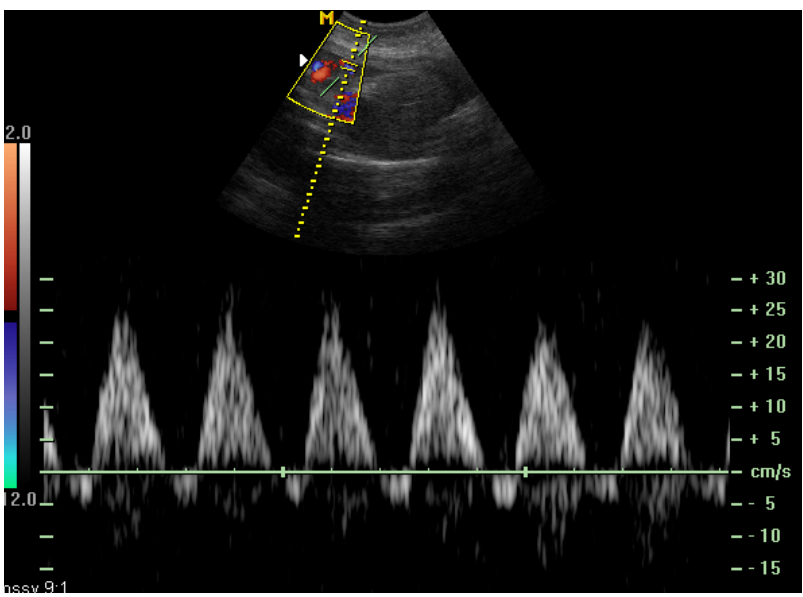

Figure 3. RF at umbilical artery Doppler. The mother was 18 years old and had pregnancy-induced hypertension. The foetus was born prematurely at 30 weeks and was a stillbirth after induction of labour. The foetal weight at delivery was less than $1.5 \mathrm{~kg}$. 
mothers were hypertensive. This is in agreement with studies which have shown that pregnancy induced hypertension; along with intrauterine foetal growth restriction (IUGR) have a significantly high association with reversal of flow (RF) or absent end-diastolic flow (AEDF) in the foetal umbilical artery [1,23,24,25].

None of the diabetic patients had foetuses with abnormal flow patterns. This is because they were very few (only 4) those who could have had abnormal flow patterns were not recruited.

AEDF/RF was associated with stillbirths or foetal death within 24 hours of delivery. $\mathrm{P}=<0.0001$ OR 38.7 $(6.61-226)$. This is reflected in Table 1. Only one of the 12 foetuses with reduced end-diastolic flow died within 24 hours of delivery. Diabetes mellitus, hypertension and IUGR are all associated with placental insufficiency which causes increased impedance of blood flow. This in turn leads to AEDF or even RF and thus increases mortality $[32,33]$.

Four of the foetuses with AEDF survived but after being admitted to the special care unit (Table 1). The rea- son why some of them survived and others died cannot be explained by this study.

Premature delivery was common among foetuses with abnormal flow patterns (Table 1). AEDF/RF was also associated with low birth weight according to Table $\mathbf{1}$. Hypertension and Diabetes in pregnancy are associated with placental insufficiency which can lead to intrauterine foetal growth restriction. This explains the majority of foetuses being of a low birth weight [1]. Literature also shows that abnormal flow patterns are associated with premature deliveries because of early obstetric intervention (Caesarian section and induction of labour) [22].

The majority of foetuses with abnormal flow patterns were born after an obstetric intervention (caesarian section or induction of labour) as seen in Table 1.

Induction of labour is also one of the obstetric interventions used in Mulago Hospital and elsewhere besides Caesarian section $[48,49]$. Most of the mothers who were recruited had an intervention and the commonest intervention was Caesarian section $(52.60 \%)$. The main rea-

Table 1. AEDF/RF and foetal outcomes.

\begin{tabular}{|c|c|c|c|c|}
\hline Variable & Total & AEDF/RF (\%) & OR (CI) & P Value \\
\hline \multicolumn{5}{|l|}{ Weight at delivery (kg) } \\
\hline$\geq 2.5$ & 131 & $0(0)$ & & \\
\hline$<2.5$ & 59 & $9(15.3)$ & & \\
\hline \multicolumn{5}{|l|}{ Apgar score } \\
\hline $0-2$ & 12 & $4(33.3)$ & & \\
\hline $5-7$ & 27 & $4(14.81)$ & $0.35(0.66-1.83)$ & 0.192 \\
\hline $8-10$ & 153 & $1(0.65)$ & $0.01(0.001-0.19)$ & 0.000 \\
\hline \multicolumn{5}{|l|}{ Primary Outcomes } \\
\hline Term & 126 & $1(0.79)$ & & \\
\hline Premature & 65 & $8(12.39)$ & $17.54(1.98-155.4)$ & 0.0004 \\
\hline \multicolumn{5}{|l|}{ Secondary outcomes } \\
\hline Good & 177 & $3(1.69)$ & & \\
\hline Stillbirth/ Death within 24 hours & 15 & $6(40)$ & $38.7(6.61-226)$ & $<0.0001$ \\
\hline \multicolumn{5}{|l|}{ Gestational age at delivery (weeks) } \\
\hline $37-42$ & 122 & $0(0)$ & & \\
\hline $28-36$ & 70 & $9(12.86)$ & & \\
\hline \multicolumn{5}{|l|}{ Obstetric Intervention } \\
\hline Yes & 154 & $8(5.19)$ & & \\
\hline No & 36 & $1(2.78)$ & $0.52(0.06-4.34)$ & 0.54 \\
\hline \multicolumn{5}{|l|}{ Type of Intervention } \\
\hline Caesarian section & 81 & $4(4.94)$ & & \\
\hline Induction & 73 & $4(5.48)$ & $1.12(0.27-4.65)$ & 0.88 \\
\hline \multicolumn{5}{|c|}{ Admission to Neonatal special care unit } \\
\hline No & 177 & $4(2.3)$ & & \\
\hline Yes & 15 & $5(50)$ & $21.6(5.2-42.1)$ & 0.00 \\
\hline
\end{tabular}


son for the caesarian section was to save the mother and baby's lives in high-risk pregnancy whether the umbilical artery Doppler flow pattern is normal or abnormal. The other intervention was induction of labour. Caesarian section is done for those mothers whose foetuses are in a poor condition because it is the quickest method of delivery. The Caesarian section rate in Mulago Hospital is $27 \%$ [9] compared to $15 \%$ recommended by WHO [50]. The reason for this is because Mulago is the national referral hospital where most of the peripheral units refer complicated cases many of which need to be managed by Caesarian section. Induction of labour is done for those mothers in a better condition and whose foetuses are not in distress. Of the foetuses with abnormal flow patterns, $88.9 \%$ had an obstetric intervention and half of these were Caesarian sections (Table 1). This study is in agreement with other studies which have shown that there is an increased Caesarian section rate in abnormal umbilical artery Doppler findings [25,51].

Several studies have also shown that abnormal umbilical artery Doppler flow patterns are associated with increased admission to the neonatal intensive care unit, perinatal morbidity and mortality $[25,48,51,52]$. This is similar to what was found out in this study: There was a better outcome among foetuses with reduced end-diastolic flow although many were born by Caesarian section. This is because when there is reduced end-diastolic flow, the foetus is not yet severely compromised and can be saved by obstetric intervention.

The good outcome realized with the foetuses with high resistance indices (Table 2) shows that in spite of this finding, the foetus can survive if delivered early. It is reported that if the resistance index is high and there is diastolic flow, it may not be significant [17] so probably some of the foetuses were not compromised.

According to the multivariate logistics model (Table 3), the foetuses with AEDF or RF were more at risk of having an adverse outcome than the ones without. Those born prematurely (28 - 36 weeks of gestation) were also more likely to have an adverse foetal outcome than those born at term. This is because of the increased mortality that has been reported in premature babies [4]. Most of the foetuses with adverse outcomes (14 out of 15) had a birth weight of less than $2.5 \mathrm{~kg}$ (Table 2). It is well known that a low birth weight is associated with a poor foetal outcome $[4,54]$. Only one of those with an adverse outcome had a weight of more than $2.5 \mathrm{~kg}$. Fourteen of the 15 foetuses with an adverse outcome had an Apgar score of 0 to 7 while only one had an Apgar score of 8 to 10 (Table 3). Low 5 minute Apgar scores are predictive of neonatal death in preterm infants [4].

Therefore apart from abnormal flow patterns, premature delivery, low birth weight and low Apgar score are associated with adverse foetal outcome.

In this study, AEDF and RF were associated with a low Biophysical profile score (Table 4).

Table 2. High resistance indices and foetal outcome.

\begin{tabular}{|c|c|c|c|c|}
\hline Gestational age at delivery & Total & High RI & OR (CI) & P-value \\
\hline $37-42$ & 94 & $14(14.89)$ & & \\
\hline $28-36$ & 56 & $20(35.71)$ & $3.17(1.40-7.17)$ & 0.00 \\
\hline \multicolumn{5}{|l|}{ Obstetric Intervention } \\
\hline Yes & 123 & $30(24.39)$ & & \\
\hline No & 26 & $4(15.38)$ & $0.56(0.18-1.78)$ & 0.32 \\
\hline \multicolumn{5}{|l|}{ Type of intervention } \\
\hline $\mathrm{C} / \mathrm{S}$ & 65 & $18(27.69)$ & & \\
\hline Induction & 58 & $12(20.69)$ & $0.68(0.29-1.58)$ & 0.37 \\
\hline \multicolumn{5}{|l|}{ Primary Outcome } \\
\hline Term & 96 & $16(16.67)$ & & \\
\hline Premature & 53 & $18(33.96)$ & $2.57(1.5-5.7)$ & 0.02 \\
\hline \multicolumn{5}{|l|}{ Secondary Outcome } \\
\hline Good & 141 & $32(22.70)$ & & \\
\hline Stillbirth & 3 & $1(33.33)$ & $1.70(0.15-19.59$ & 0.85 \\
\hline Death within 24 hours & 6 & $1(16.67)$ & $0.68(0.76-6.09)$ & 0.85 \\
\hline \multicolumn{5}{|l|}{ Apgar Score } \\
\hline $0-2$ & 7 & $1(14.29)$ & & \\
\hline $5-7$ & 21 & $4(19.05)$ & $1.41(0.12-16)$ & 0.77 \\
\hline $8-10$ & 122 & $29(23.77)$ & $1.87(0.21-16.36)$ & 0.48 \\
\hline
\end{tabular}


Table 3. Multivariate logistic model results.

\begin{tabular}{|c|c|c|c|c|}
\hline Variable & Total & Adverse outcome (\%) & AOR (95\%CI) & Pvalue \\
\hline \multicolumn{5}{|l|}{ AEDF/RF } \\
\hline No & 183 & $9(4.9)$ & & \\
\hline Yes & 9 & $6(66.7)$ & $9.3(2.2-92 . .47)$ & 0.005 \\
\hline \multicolumn{5}{|c|}{ Gestational age at delivery (weeks) } \\
\hline $28-36$ & 70 & $11(15.7)$ & & \\
\hline $37-42$ & 122 & $4(3.3)$ & $0.014(0.001-0.02)$ & $<0.001$ \\
\hline \multicolumn{5}{|c|}{ Birth weight* } \\
\hline$<2.5 \mathrm{~kg}$ & 59 & $10(17.0)$ & & \\
\hline$\geq 2.5 \mathrm{~kg}$ & 131 & $4(3.1)$ & $9.58 \mathrm{e}-08$ & \\
\hline \multicolumn{5}{|c|}{ Apgar score* } \\
\hline $8-10$ & 153 & $1(0.7)$ & & \\
\hline $0-7$ & 39 & $14(35.9)$ & $4.06 \mathrm{e}+15$ & \\
\hline
\end{tabular}

Table 4. AEDF/RF and the biophysical profile score.

\begin{tabular}{ccccc}
\hline Variable & Total & $\begin{array}{c}\text { AEDF/RF } \\
(\mathbf{\%})\end{array}$ & $\begin{array}{c}\text { COR } \\
(\mathbf{9 5 \%} \mathbf{C I})\end{array}$ & P Value \\
\hline $\begin{array}{c}\text { Biophysical } \\
\text { profile score }\end{array}$ & & & & \\
$8-10$ & 146 & $4(2.74)$ & & \\
$0-6$ & 46 & $5(10.87)$ & $4.32(1.1-17.2)$ & 0.023 \\
\hline
\end{tabular}

Foetuses with abnormal flow patterns usually have a poor outcome (Table 3). A low biophysical profile score is also associated with a poor foetal outcome because there is a high probability of foetal asphyxia with a score of $4-6$, and it is almost certain with a score of 0 or 2 [1].

Most of the foetuses with reduced end-diastolic flow and those with high resistance indices had a Biophysical profile score of $8-10$ because they were not yet severely compromised (Table 5). This is in agreement with a study in Kenya which showed that Doppler ultrasound is more sensitive than the biophysical profile score in detecting foetal compromise [12] since the Doppler findings were abnormal before the Biophysical profile.

According to the American College of Obstetricians and Gynecologists (1999) there is no 'best test' to evaluate foetal well-being. Therefore the Biophysical profile should be used together with umbilical artery Doppler Ultrasound to assess foetal well-being [55].

In conclusion, Doppler ultrasound of the foetal umbilical artery is important in predicting foetal outcome and reducing on perinatal mortality. Therefore there is need to avail ultrasound machines with Doppler application to hospitals with maternity units and to train more health personnel in using them.

\section{CONCLUSIONS}

- The prevalence of abnormal umbilical artery flow
Table 5. High resistance indices and the biophysical profile score.

\begin{tabular}{ccccc}
\hline $\begin{array}{c}\text { Biophysical } \\
\text { profile }\end{array}$ & Total & High RI (\%) & OR (CI) & P Value \\
\hline $0-6$ & 38 & $9(23.7)$ & & \\
$8-10$ & 112 & $25(22.32)$ & $1.4(0.44-4.61)$ & 0.39 \\
\hline
\end{tabular}

patterns in high-risk pregnancy at Mulago Hospital is $10.95 \%$ (Reduced end-diastolic flow $=6.25 \%$, AEDF $=4.2 \%$ and $\mathrm{RF}=0.5 \%$ ) from this study.

- AEDF and RF are related to poor foetal outcome.

- Foetuses delivered before reduced end-diastolic flow converting to AEDF or RF have better outcomes.

- High resistance indices may not predict a poor foetal outcome.

- There is a relationship between a low biophysical profile score and AEDF/RF.

\section{Recommendations}

- Umbilical artery Doppler ultrasound and Biophysical profile should be done routinely for all high-risk pregnancies above 28 weeks.

- Radiologists and Obstetricians should be trained in the use of Umbilical artery Doppler ultrasound because it aids in reducing perinatal mortality and predicting foetal outcome.

- Ultrasound machines with Doppler application should be available in all hospitals where high-risk pregnancies are managed.

- Studies including malaria and multiple pregnancies, with longer follow-up periods should be done to find out the trend in these conditions and any other long term complications in foetuses with abnormal flow patterns. 


\section{ACKNOWLEDGEMENTS}

We wish to thank the following people for their support. The director Mulago Hospital, Kampala for waiver of the ultrasound examinations. The Radiologists and Postgraduates in Mulago Hospital and Makerere University for their input in the research proposal and dissertation. Dr Dan Kaye, Obstetrician and senior lecturer Makerere University for his expert advice. Makerere University College of Health Sciences under which this research was done.

\section{REFERENCES}

[1] Merz, E. (2005) Ultrasound in obstetrics and gynaecology. 2nd Edition, Mainz, Georg Thieme, New York, 507-513.

[2] Reed, K.L. (1990) Ultrasound in obstetrics. In: Scot, J.R., Disaia, P.J., Hammond, C.B. and Spellacy, Eds., Danforth's Obstetrics and Gynecology, 6th edition, J.B Lippincott Company, 293.

[3] Ministry of Health and Uganda National Drug Authority (2003) Uganda clinical guidelines. Ministry of Health and Uganda National Drug Authority, Kampala, 278.

[4] Cunningham, F.G., Leveno, K.J., John, S.B., Hauth, C., Gilstrap, III and Wenstrom, K.D. and Williams (2005) Obstetrics. 22nd edition, McGraw-Hill Companies, New York, 373-387.

[5] Bekedam, D.J., Visser, G.H.A., van der Zee, Snijders R.J.M. and Poelmann-Wesjes, G. (1990) Abnormal velocity waveforms of the umbilical arteries in growth-retarded fetuses: Relationship to antepartum late heart rate decelerations and outcome. Early Human Development, 24, 79-89. http://dx.doi.org/10.1016/0378-3782(90)90008-7

[6] Neilson, J.P. and Alfrevic, Z. (1996) Doppler ultrasound for fetal assessment in high-risk pregnancies. Cochrane Database of Systematic Reviews, 4, Article ID:CD00073. http://dx.doi.org/10.1002/14651858

[7] World Health Organization (2006) Neonatal and perinatal mortality (country, regional and global estimates). World Health Organization.

[8] Ministry of Health Uganda (2004) Health sector strategic plan 200/01-2004-05. Ministry of Health Uganda, Kampala, 26.

[9] Neonatal Special Care Unit of Mulago Hospital (2007) Mulago Hospital Neonatal Special Care Unit records. Mulago Hospital, Kampala.

[10] Chireu, M., Hartmann, K.E., Berkman, N., et al. (2002) Academic Health Services Policy Meet, 19, 4.

[11] Velez, D.R., Fortunato, S.J., Morgan, N., et al. (2008) Patterns of cytokine profile differ with pregnancy outcome and ethnicity. Human Reproduction, 23, 1902-1909. http://dx.doi.org/10.1093/humrep/den170

[12] Nguku, S.W., Wanyoike-Gichuhi, J. and Aywak, A.A. (2006) Biophysical profile scores and resistance indices of the umbilical artery as seen in patients with pregnancy-induced hypertension. East African Medical Journal, 83, 96.

[13] Neonatal Special Care Unit of Mulago Hospital (2008) Mulago Hospital Neonatal Special Care Unit records. Mulago Hospital, Kampala.
[14] FitzGerald, D.E. and Drumm, J.E. (1977) Non-invasive measurement of human circulation using ultrasound: A new method. BMJ, 2, 1450. http://dx.doi.org/10.1136/bmj.2.6100.1450

[15] Campbell, et al. (1983) Uteroplacental circulation: Dupplex scanner. Lancet.

[16] Mcgrath-Ling, M. (1997) Fetal well-being and fetal death. In: Sanders, R.C. and Miner, N.S., Eds., Clinical Sonography, Lippincott Williams \& Wilkins, Baltimore, 173182.

[17] Biljan, M., Haddad, N., McVey, K., et al. (1992) Efficiency of continuous wave Doppler in screening high risk pregnancies in a district general hospital (a prospective randomized study of 674 singleton pregnancies). Proceedings of 26th British Congress of Obstetrics and Gynaecology, Manchester, 19 August 1992.

[18] Burke, G., Stuart, B., Crowley, P., et al. (1992) Does Doppler ultrasound alter the management of high risk pregnancy? Care, concern and cure in perinatal medicine. Parthenon, Carnforth, Amsterdam, 12-15 March 2013.

[19] Johnstone, F.D., Prescott, R., Hoskins, P., et al. (1993) The effect of introduction of umbilical Doppler recordings to obstetric practice. British Journal of Obstetrics and Gynaecology, 100, 733. http://dx.doi.org/10.1111/j.1471-0528.1993.tb14264.x

[20] Tyrell, S.N., Lilford, J., MacDonald, H.N., et al. (1990) Randomised comparison of routine vs. highly selective use of Doppler ultrasound and biophysical scoring to investigate high risk pregnancies. British Journal of Obstetrics and Gynaecology, 97, 909-916. http://dx.doi.org/10.1111/j.1471-0528.1990.tb02446.x

[21] Neales, K., Motteram, J. and Maxwell, D. (1994) A randomised controlled trial to assess the use of Doppler ultrasound in the management of patients with intrauterine growth retardation. Personal Communication, 24 January 1994.

[22] Nienhuis, S.J. (1995) Costs and effects of Doppler ultrasound measurements in suspected intrauterine growth retardation. A randomised clinical trial. MD Thesis, Universitaire pers Maastrich, Maastricht.

[23] . Hofmeyr, G.J., Pattinson, R., Buckley, D., et al. (1991) Umbilical artery resistance index as a screening test for fetal wellbeing I, Randomised feasibility study. Obstetrics and Gynaecology, 76, 359.

[24] Newnham, J.P., O’Dea, M.R., Reid, K.P., et al. (1991) Doppler flow velocity waveform analysis in high risk pregnancies: A randomised controlled trial. British Journal of Obstetrics and Gynaecology, 98, 956-963. http://dx.doi.org/10.1111/j.1471-0528.1991.tb15332.x

[25] Almstrom, H., Axelson, O., Cnattingius, S., et al. (1992) Comparison of umbilical artery velocimetry and cardiotocography for surveillance of small-for-gestational age fetuses. A multicentre randomised controlled trial. Lancet, 340, 936.

[26] Trudinger, B.J., Cook, C.M., Giles, W.B., et al. (1987) Umbilical artery flow velocity waveforms in high-risk pregnancy: Randomised controlled trial. Lancet, 1, 188190. http://dx.doi.org/10.1016/S0140-6736(87)90003-1

[27] Pattinson, L., Norman, K. and Odendaal, H.J. (1992) The 
role of Doppler velocimetry in the management of pregnancies: A randomised controlled trial. Proceedings of 11th Conference on Priorities in Perinatal Care in South Africa, 59.

[28] Murray, C. and Lopez, A. (1998) Health dimensions of sex and reproduction. Vol. 3, Global burden of disease and injury series. Harvard University Press, Boston, 219.

[29] Jimmenez, M.J., Bueno Cavanillas, A., Luna Des Castillo, J.D., et al. (2000) Predictive value of screen for GDM, influence of associated risk factors. Acta Obstetricia et Gynecologica Scandinavica, 79, 991.

[30] Giles, W.B., Trudinger, B.J. and Blaird, P. (1985) Fetal umbilical artery flow velocity waveforms and placental resistance: Pathologic correlation. BJOG, 92, 31-38. http://dx.doi.org/10.1111/j.1471-0528.1985.tb01045.x

[31] Macara, L., Kingdom, J.C. and Kaufmann, P. (1996) Structural analysis of placental terminal villi from growth-restricted pregnancies with abnormal umbilical artery Doppler waveforms. Placenta, 17, 37. http://dx.doi.org/10.1016/S0143-4004(05)80642-3

[32] de Onism, M., Blosner and Villar, J. (1998) Levels and patterns of intrauterine growth retardation in developing countries. European Journal of Clinical Nutrition, 52, 55.

[33] UNICEF (1998) The state of the world's children 1998. Oxford University Press, New York.

[34] Tamura, R.K., Sabaggha, R.E., Depp, R., et al. (1986) Diabetic macrosomia. Accuracy of third trimester ultrasound. Obstetrics \& Gynecology, 67, 826-832.

[35] Campbell, S. (1974) The assessment of foetal development by diagnostic ultrasound. In: Milunsky, A., Ed., Clinics in Perinatology, Saunders, Philadelphia, 507.

[36] Crane, J.P. and Kopta, M.M. (1979) Prediction of intrauterine growth retardation via ultrasonographic measurement of head/abdominal circumference ratios. obstetrics \& Gynecology, 54, 597-601.

[37] Campbell, S. and Thoms, A. (1977) Ultrasound measurement of the foetal head to abdomen circumference ratio in the assessment of growth retardation. British Journal of Obstetrics \& Gynecology, 84,165-174. http://dx.doi.org/10.1111/j.1471-0528.1977.tb12550.x

[38] Little, D. and Campbell, S. (1982) Ultrasonic evaluation of intrauterine growth retardation. Radiologic Clinics of North America, 20, 335.

[39] Queenan, J.T., Kabarych, S.F., Cook, L.B., et al., (1976) Diagnostic ultrasound for detection of intrauterine growth retardation. American Journal of Obstetrics and Gynecology, 124, 865.

[40] Whetham, J.C., Muggah, H. and Davidson, S. (1976) Assessment of intrauterine growth retardation by diagnostic ultrasound. American Journal of Obstetrics and Gynecology, 125, 577-580.

[41] Chang, T.C., Robson, S.C., Boys, R.J. and Spencer, J.A. (1992) Prediction of the small for age infant: which ultrasonic measurement is best? Obstetrics \& Gynaecology, 80, 1030-1038.

[42] Kish and Leslie (1965) Survey sampling. John Wiley and Sons, New York.
[43] McGrath Ling, M. (1991) Fetal death and sickness, In: Sanders, R.C., Ed., Clinical Sonography, A Practical Guide, 2nd Edition, Little, Brown and Company, Boston, 163168.

[44] Maggio, M. and Sanders, R. (1991) Doppler Principles, In: Sanders, R., Ed., Clinical Sonography, A Practical Guide, 2nd Edition, Little, Brown and Company, Boston, 25-31.

[45] Hauth, J.C., Ewell, M.G., Levine, R.J., Esterlitz, J.R., Sibai, B., Curet, L.B., Catalano, P.M. and Morris, C.D. (2000) Pregnancy outcomes in healthy nulliparas who developed hypertension. Obstetrics and Gynecology, 95, 24-28. http://dx.doi.org/10.1016/S0029-7844(99)00462-7

[46] Vatten, L.J. and Skajaerven, R. (2004) Is pre-eclampsia more than one disease? British Journal of Obstetrics \& Gynecology, 111, 298-302. http://dx.doi.org/10.1111/j.1471-0528.2004.00071.x

[47] UNICEF Uganda Statistics (2007)

[48] World Health Organization (1985) Appropriate Technology for birth. Lancet, 2, 436-437.

[49] Spinillo, A., Montanari, L., Bergante, C., Gaia, G., Chiara, A. and Fazzi, E. (2005) Prognostic value of Umbilical Artery Doppler studies in unselected preterm deliveries. $\mathrm{Ob}$ stetrics and Gynecology, 105, 613-620. http://dx.doi.org/10.1097/01.AOG.0000152382.13490.18

[50] Boschert, S. (2000) Umbilical Doppler studies predict fetal outcome. OB GYN News, 15 June 2000.

[51] Devendra, A., Desai Sadhana, K., Sheth Prem, N. and Prema, K. (2005) Significance of Umbilical Artery Velocimetry in perinatal outcome of growth restricted fetuses. Journal of Obstetrics \& Gynecology of India, 55, 138-143.

[52] Johnston, F.D., Prescott, R., Hoskins, P., Greer, I.A., McGlew, T. and Compton, M. (1993) The effect of introduction of umbilical Doppler recordings to obstetric practice. British Journal of Obstetrics \& Gynecology, 100, 733-741.

[53] Seyam, Y.S., Al-Mahmeid, M.S. and Al-Tamimi, H.K. Intrauterine growth restriction and its relation to perinatal outcome.

[54] Byun, Y.J., Kim, H., Yang, J., Kim, J.H., Kim, H.Y. and Chang, S.J. (2009) Umbilical Artery Doppler study as a predictive marker of perinatal outcome in preterm small for gestational age infants. Yongei Medical Journal, 50, 39-44. http://dx.doi.org/10.3349/ymj.2009.50.1.39

[55] Jouppila, P. Kirkinen, P. (1984) Increased vascular resistance in the descending aorta of the human foetus in hypoxia. British Journal of Obstetrics \& Gynecology, 91, 853-856.

http://dx.doi.org/10.1111/j.1471-0528.1984.tb03696.x

[56] Franko, K., Gluckman, P., Law, C., Beedle, A. and Morton, S. (2009) Low birth weight and optimal foetal development, In: Kiess, W. Chermausek, S.D. and Hokken-Koelega A.C.S., Eds., Small for Gestational Age, Causes and Consequences, Archives of Pediatrics and Adolescent Medicine, Basel, Karger.

[57] American College of Obstetricians and Gynecologists (1999) Antepartum Fetal Surveillance Practice Bulletin. Washington DC. 